\title{
Políticas educacionais e juventude rural no ensino superior
}

\section{Educational policies and rural youth in higher education}

\author{
Ezequiel Redin ${ }^{1}$
}

\begin{abstract}
RESUMO
$\mathrm{O}$ artigo objetiva analisar as políticas educacionais de acesso ao ensino superior, recentemente instituídas no Brasil, em especial, o Programa Universidade para Todos (Prouni) e as relações com a juventude rural, hipossuficiente economicamente. As informações usadas referem-se aos dados institucionais do poder público federal e as reflexões sobre os jovens rurais, bolsistas, com base no Território Centro-Serra, Rio Grande do Sul. O estudo possibilitou identificar que o Prouni proporcionou uma oportunidade à juventude rural de cursar o ensino superior em instituições de ensino particulares, porém, a maioria dos jovens rurais ainda permanece em condição marginal no acesso à política educacional, principalmente, pelo capital cultural herdado da condição camponesa em que o hábito da leitura, do acesso a livros e da dedicação aos estudos encontra-se num duelo com o trabalho na roça, estratégia fundamental para manter a reprodução social da família rural. O Prouni representa, em certa medida, a universalização e a democratização do acesso ao ensino superior em nível regional, o que proporcionou a qualificação profissional de parcela da juventude rural mantendo seus laços com o território e fortalecendo o capital cultural. Porém, a política educacional é invisível à categoria social e insuficiente para proporcionar amplo acesso aos jovens rurais e à juventude em geral que demanda qualificação de nível superior.

Palavras-chave: IES; ensino superior; juventude rural; políticas educacionais.
\end{abstract}

DOI: $10.1590 / 0104-4060.44861$

1 Faculdade Metodista de Santa Maria. Santa Maria, Rio Grande do Sul, Brasil. Rua Dr. Turi, nº 2003. Centro. CEP: 97050-180.E-mail: ezequielredin@gmail.com 


\begin{abstract}
This article aims to analyze educational policies of access to higher education, which were recently introduced in Brazil, in particular the Programa Universidade para Todos (Prouni) and its relations with rural youth, that is an economic disadvantage. The information used refers to the institutional data from the federal government and the reflections on rural youth, scholars, based in the Territory Centro-Serra, Rio Grande do Sul. The study identified that Prouni provided an opportunity to the rural youth attend higher education in private educational institutions, however, the majority of rural youth remains in a marginal condition in relation to their access to that educational policy, mainly by the cultural capital inherited from their peasant condition in which habits of reading, access to books and dedication to studies are in a duel with the work in the fields, a fundamental strategy to maintain social reproduction of rural families. Prouni is, to some extent, the universalization and democratization of access to higher education at the regional level, which provided professional qualification to a portion of the rural youth keeping their ties with the territory and strengthening the cultural capital. However, that educational policy is invisible to that social category and it is insufficient to provide broad access to the rural youth and youth in general who demand higher education levels.
\end{abstract}

Keywords: IES; higher education; rural youth; educational policies.

\title{
Introdução
}

Historicamente, o Estado é uma instituição que rege os meios, os métodos e o acesso da sociedade à educação por meio de uma maior ou menor intervenção pública, ações que revelam estratégias ou as prioridades do país em determinado período. No Brasil, o acesso ao ensino superior à sociedade rural foi restrito. Em 1968, foi criada a Lei $n^{\circ} 5.465$, de 3 de julho de 1968, que vigorou sobre a reserva de, preferencialmente, $50 \%$ das vagas nos estabelecimentos de ensino médio agrícola e nas escolas superiores de Agricultura e Veterinária, mantidos pela União, para candidatos agricultores ou filhos destes, proprietários ou não de terras, que residiam com suas famílias na zona rural e 30\% a agricultores ou filhos destes, proprietários ou não de terras, que residiam em cidades ou vilas que não possuam estabelecimentos de ensino médio. (BRASIL, 1968). Em 1985, a "Lei do Boi” foi revogada pela Lei no 7.423, de 1985. (BRASIL, 1985). Uma das principais críticas dessa reserva de vagas é que beneficiava, principalmente, os filhos de agricultores com privilegiadas posses de imóveis 
rurais, em particular, os fazendeiros. Se, por um lado, qualificava os herdeiros da propriedade, por outro, estimulava a separação de classes no meio rural. A segregação social e a preservação da dominação de classes provoca um pensamento dual de que as cotas de vagas nas universidades devem partir do princípio da igualdade perante os candidatos.

Em 2004, o governo federal criou o Programa Universidade para Todos (Prouni) que foi institucionalizado pela Lei $\mathrm{n}^{\circ}$ 11.096, em 13 de janeiro de 2005, com o objetivo de conceder bolsas de estudo integrais e parciais em cursos de graduação e sequenciais de formação específica, em instituições de ensino superior privadas. (BRASIL, 2005). Por um lado, se estimula e amplia o acesso às universidades públicas pelas pessoas carentes e, por outro, isenta de tributação as instituições que aderem ao Programa.

Nesse sentido, as políticas educacionais, nos últimos anos, buscam um processo de equalização das disparidades de acesso ao ensino superior, primando pelo ingresso de uma parcela de candidatos que possuem baixa renda familiar. Aliado a isso, a expansão do Ensino Superior público proporcionou um incremento de vagas nas instituições superiores, bem como a criação de novas IES sob condução do Programa de Apoio a Planos de Reestruturação e Expansão das Universidades Federais (Reuni) e por intermédio da Educação a Distância (EAD) pública e gratuita via Universidade Aberta do Brasil (UAB). Essas ações, em especial nos últimos dez anos, têm possibilitado um acréscimo das oportunidades para a sociedade acessar aos cursos superiores.

A reflexão sobre o tripé - ensino superior, juventude rural e políticas educacionais - foi realçada pela vivência no cotidiano rural que, em certa medida, iniciou um processo de estímulo para que os jovens rurais tivessem acesso a cursos superiores nos municípios circunvizinhos que possuem instituições privadas. A região Centro-Serra ${ }^{2}$, do estado do Rio Grande do Sul, não possui universidade pública, fato que possibilita três opções: a) migrar em busca do ensino superior público em outras regiões, b) atualmente, cursar alguns poucos cursos ofertados a distância pela Universidade Aberta do Brasil (UAB), ou c) permanecer no local e/ou migrar estudando numa instituição superior privada. A demanda regional por um instituto técnico tem sido pauta nos últimos cinco anos, fato percebido pelos agentes públicos como um dos principais motes para o desenvolvimento regional e também para minimizar o êxodo de jovens da região. Para tanto, diante dessa realidade, procura-se identificar, neste estudo, quais os reflexos do Prouni na vida da juventude rural de baixa renda, em especial, vinculada à agricultura familiar? Para responder essa questão, utilizam-se

2 A Região Centro-Serra é composta pelos municípios de Arroio do Tigre, Estrela Velha, Ibarama, Lagoa Bonita do Sul, Lagoão, Passa Sete, Segredo, Sobradinho e Tunas. 
de dados secundários do governo federal e da reflexão sobre os jovens rurais que acessaram o programa e permaneceram na propriedade e também jovens rurais que acessaram o programa e que migraram para outras regiões. A escolha deste local para o estudo pautou-se, especialmente, no conhecimento prévio do território e dos agentes locais, pela carência de instituições públicas de ensino superior e pela presença de jovens rurais cotistas do Prouni. Para esta investigação, por juventude rural entendem-se aqueles que estão com idade entre 15 e 29 anos, tipologia referência para as políticas públicas do estado brasileiro. Segundo Carvalho e Rossetto (2014), atualmente, são oito milhões de jovens rurais que estão nesta faixa etária no Brasil, fato que motivou a construção de políticas públicas específicas para este segmento social. O objetivo do trabalho é analisar as políticas educacionais de acesso ao ensino superior, recentemente instituídas no Brasil, em especial, o Programa Universidade para Todos (Prouni) e as relações com a juventude rural, hipossuficiente economicamente. A partir dessa perspectiva, a pesquisa recorre às contribuições de Pierre Bourdieu e Amartya Sen.

\section{Políticas educacionais, desenvolvimento e as cotas nas IES privadas}

O desenvolvimento é um processo de expansão das liberdades reais em que as pessoas possam desfrutar, sendo que a expansão da liberdade é o fim primordial e o principal meio do desenvolvimento, conforme perspectiva do economista Sen (2000). A perspectiva humanista de Amartya Sen convoca a interpretar o desenvolvimento para além das noções econômicas, com foco nas questões sobre a pobreza, a fome e o bem-estar social. Nessa perspectiva, a liberdade é uma condição sine qua non para avaliar a natureza do desenvolvimento, e a variável capacidade é a determinação de uma função alternativa no processo de escolha do indivíduo.

Nessa abordagem, o desenvolvimento de um país pode ser medido conforme as oportunidades que a sociedade tem disponível para escolha. No Brasil, o acesso ao ensino superior até o final da década de 1990 era privilégio das famílias com boas condições econômicas que, em especial, tinham estrutura para custear o filho em outra cidade e manter os estudos superiores, sejam no âmbito de instituições públicas, quanto nas privadas. O investimento realizado pela família para a busca de um diploma superior era alto, estratégia cabível para a diferenciação social. Na França, o sociólogo Pierre Bourdieu identificou que as estratégias educativas são uma forma de reprodução social das famílias, 
aquelas que envolvem o uso da educação e conhecimento formal (escolas) e a ética que determinam o comportamento da família, como o fato de influenciar os filhos a estudar, como uma estratégia de investimento em longo prazo, e prepará-los para receber a herança. (BOURDIEU, 2011).

No meio rural, o estudo era considerado secundário para desempenhar as atividades agrícolas que exigiam, em especial, força física. O incremento de tecnologia agrícola no campo e as evoluções na modernização do aparato proporcionaram metamorfoses nas relações produtivas e sociais no espaço rural. Nessa reorganização social, o meio rural tem ganhado relevância para a formação de técnicos e agentes de desenvolvimento. Para as famílias rurais de baixa renda, a ampliação do acesso às políticas educacionais amenizou a responsabilidade dos pais em relação a própria culpabilização do grupo familiar não possuir dinheiro suficiente para pagar uma universidade aos filhos. Em certa medida, nessa linha de raciocínio, basta apenas os filhos estudarem para conseguirem ingressar no ensino superior com bolsa do Prouni ou, em outro caso, em instituições públicas. Na prática, a realidade evidencia grandes discrepâncias nesse tipo de pensamento, pois as oportunidades são restritas pelas poucas vagas existentes, bem como, o alto nível de competição entre os candidatos. Se o Prouni ampliou a possibilidade de estudar geograficamente próximo a casa da família, por outro lado, também possibilitou romper barreiras espaciais no momento da seleção de ingresso, pois as vagas são escolhidas em nível nacional, o que potencializa grande disputa, mesmo que, preferencialmente, se a escolha está direcionada a uma instituição próxima de seu local de moradia.

No Brasil, a restrição ao acesso ao ensino superior consagrou-se como um apartheid social, majoritariamente facilitado pela ordem econômica da família em incrementar capital cultural e social em seus herdeiros. Essa determinação social com viés eminentemente econômico conduziu a uma divisão de classes. No caso brasileiro, com respaldo legal da Lei $\mathrm{n}^{0} 11.096$, em 13 de janeiro de 2005, as instituições privadas de ensino superior passaram a conceder bolsas de estudo integrais e parciais ( $50 \%$ ou $25 \%$ ) para estudantes respaldados no critério de renda. Para acessar a bolsa integral, a renda familiar mensal per capita não pode exceder o valor de até um salário-mínimo e meio, enquanto que para acessar as bolsas de estudo parciais de $50 \%$ ou de $25 \%$ a renda familiar mensal per capita não pode exceder o valor de até três salários-mínimos. (BRASIL, 2005).

Em 2005, no primeiro ano da implementação do Prouni, as críticas sociológicas eram acentuadas. Catani e Gilioli (2005) afirmam que o programa alia a cidadania e a privatização e fortalece as instituições privadas em detrimento das IES públicas. Em 2006, Catani, Hey e Gilioli criticam o Prouni de forma a igualar a uma política pública, especialmente, porque abrigou o preceito das cotas, além do Estado orientar-se para um sistema de ensino nos moldes privatizantes 
traçados durante os anos 1990, o que traz uma noção falsa de democratização e contribui para a manutenção da estratificação social existente ao inseriram os pobres num espaço delgadamente privado. (CATANI; HEY; GILIOLI, 2006).

Nessa perspectiva, os autores defendem que os investimentos em educação superior devem se concentrar nas IES públicas como forma de potencializar esse espaço de ensino em detrimento do capital privado. Anos posteriores, o governo federal potencializa o Reuni e a EAD por intermédio da UAB. Essas ações criaram inúmeras universidades públicas no país, além de investir fortemente no ensino superior público.

Para o público beneficiário, inclui-se aqui a juventude rural, o Prouni tem outra interpretação. Redin e Silveira (2012), no estudo sobre a juventude rural em Arroio do Tigre, apontam que o Prouni fortaleceu o sonho do jovem rural cursar ensino superior em universidades particulares. Tanto o Prouni quanto a EAD possibilitaram aos jovens investir em ensino superior sem a necessidade de migrar para outras regiões, pois os jovens rurais tiveram a oportunidade de cursar ensino superior sem necessariamente sair da propriedade. Porém, os autores alertam que isso não é uniforme em todos os cenários e regiões. (REDIN; SILVEIRA, 2012). Nesse sentido, para os jovens de baixa renda, tanto rurais quanto urbanos, é uma oportunidade de transcender em busca de qualificação, seja com intuito de utilizar na unidade de produção ou trabalhar na própria região como agente de desenvolvimento. Nessa perspectiva, o jovem fortalece o capital cultural no território e a política educacional potencializa ampliar e oportunizar que locais distantes dos grandes centros universitários no Rio Grande do Sul também tenham acesso ao ensino superior.

Para a juventude rural, o Prouni é uma estratégia de ultrapassar a fronteira simbólica entre o estudado e o não estudado, pois o ensino superior significa uma ressignificação do seu papel na sociedade, percebido como um indivíduo detentor de méritos ao conquistar uma autorização, através do diploma, para o mundo do trabalho. A política educacional é um instrumento oxigenador do meio rural, pois o acesso dos herdeiros ao Prouni abre novas formas de qualificação e reinterpretação da lógica econômica da unidade de produção. Nesse sentido, esta análise se filia à lógica da universalização do ensino superior como instrumento que contribui para os processos de desenvolvimento dos territórios com características rurais.

A democratização do acesso ao ensino superior é uma pauta reivindicatória da sociedade, em especial. O Prouni provoca controvérsias e, ao mesmo tempo, coalizões. Por um lado, Oliven (2012) expõe que existe uma postura que defende uma concepção universalista dos serviços públicos e outra que alega que é uma forma de minimizar as desigualdades raciais no Brasil, através de políticas públicas diferenciais como estratégias relevantes no cenário das desigualdades 
econômicas e sociais. Oliven (2012) postula que as políticas universalistas são relevantes para melhorar a distribuição de renda, bem como os serviços públicos para a população em geral também são necessários para que o Brasil possa tornar-se uma sociedade mais igualitária.

Nesse sentido, combater as privações das sociedades rurais é uma pauta emergente. A saída do jovem rural em busca de qualificação e oportunidades fora do meio rural torna-se um problema social, porém, poucas são as ações nas regiões interioranas que estimulem a sua permanência em termos de educação profissional de nível técnica e superior. (REDIN; SILVEIRA, 2012). Diante disso, as políticas educacionais cumprem uma função social quando oferecem oportunidades às pessoas para qualificação. Adiante, será tratado sobre a relação do Prouni com a juventude rural.

\section{Prouni e juventude rural: acesso, oportunidades e desafios}

Conforme dados disponibilizados pelo Sisprouni, no estado do Rio Grande do Sul foram computados 114.558 bolsistas entre 2005 até o segundo semestre de 2014 como beneficiários da política educacional. (SISPROUNI, 2015). Segundo Andrés (2008), a distribuição das vagas anuais oferecidas pelo Prouni considera reserva de cotas para determinados estratos populacionais, como os afrodescendentes, os indígenas e os portadores de deficiência, cujas taxas de atendimento anual, no nível superior, são ainda muito acanhadas. (ANDRÉS, 2008). No que tange a juventude rural, hipossuficiente economicamente, baseada num processo histórico de marginalização da agricultura de base familiar que não é incluída na política educacional. Os fatores que podem explicar a não inserção das cotas para a juventude rural remetem a sua invisibilidade, bem como a compreensão de que essa categoria social possa estar contemplada na política educacional na condição exclusiva de baixa renda.

Nas gerações anteriores, a maioria dos filhos de agricultores familiares projetava sua vida no meio rural com pouca ou nenhuma qualificação. Neste momento, em contraponto, boa parte dos herdeiros já possui, no mínimo, o ensino médio, e outros já almejam formação superior. Há jovens rurais que buscam no ensino superior uma forma de suplantar as precárias condições financeiras do núcleo familiar. Em alusão a Sen (2000), é uma tentativa de superar a privação das capacidades básicas em vez de compreendê-la meramente como baixo nível de renda.

Nesse sentido, ainda há de se considerar que as moças têm maior pretensão de continuar os estudos em nível superior do que os rapazes do meio rural. (RE- 
DIN; SILVEIRA, 2012; REDIN, 2012; REDIN, 2015). Para as moças do meio rural, segundo Stropasolas (2014), dar sequência aos estudos em nível superior significa ter uma profissão, isto é, ter reconhecimento profissional, condição que se coloca como imprescindível para que se adquira o reconhecimento social. A questão parece similar em toda a juventude, não exclusivamente rural. No caso da política educacional analisada, se observa nos dados do Sisprouni que do segundo semestre de 2005 até o final de 2014, os dados do Prouni por sexo revelam que $47 \%$ (706.557) são do gênero masculino e 53\% (790.668) do sexo feminino 3 .

Os estudantes rurais das classes baixas, hipossuficientes economicamente, público da política educacional, têm baixo capital linguístico, poucas informações sobre o acesso às universidades, são provenientes de escolas públicas com qualificação aquém das escolas dos grandes centros e também não possuem condições de investir num curso pré-vestibular para aumentar a qualificação e as chances de conseguir uma boa nota nos processos seletivos, em especial, no Exame Nacional do Ensino Médio (Enem). A prova exige habilidades e competências com acentuado grau de interpretação e raciocínio rápido. A baixa preparação para realização da prova reverte-se numa baixa pontuação final, o que diminui a possibilidade de conseguir um bom curso numa instituição próxima da sua região. $O$ grau de dificuldade da seleção para admissão e acesso às IES privadas e públicas tem aumentado com o constante aperfeiçoamento do exame nacional. Para Bourdieu e Passeron (2011) no estudo do sistema escolar francês, o sistema de ensino fortalece a função conservadora da sociedade, pois mascara oportunidades de acesso em oportunidades de êxito. (BOURDIEU; PASSERON, 2011, p. 195). O passado escolar do jovem rural é determinante quanto aos seus diferenciais de êxito ou eliminação que disso decorrem na disputa de uma bolsa do Prouni.

A juventude rural que intenciona cursar o ensino superior em universidades privadas com bolsas do Prouni não necessariamente possui amplas opções de escolha do curso. Geralmente, suas escolhas estão restritas a um limiar de poucos cursos oferecidos pelas IES privadas e desligados com a realidade rural. As instituições privadas com unidades em regiões interioranas comumente disponibilizam cursos que necessitam de poucos investimentos, em especial, se condicionam de biblioteca, infraestrutura, docentes e laboratórios de informática. Essas instituições, geralmente, oferecem cursos de administração, direito, ciências contábeis e pedagogia ao público da região. Nesse sentido, o jovem rural, candidato à bolsa, tem poucas opções de escolha com a nota do Enem em seu território.

3 Não é possível fazer correlações sobre a relação direta entre o acesso das moças e rapazes do meio rural ao Prouni pela carência de dados. 
As condições do trabalho rural colocam a família numa encruzilhada entre o trabalho na lavoura e a qualificação profissional. A leitura não é um hábito conquistado nesse espaço, pois as prioridades na agricultura envolvem os trabalhos físicos e menos intelectuais. Nesse sentido, o jovem candidato a uma bolsa do Prouni ou até mesmo após ingressar como bolsista, tem um menor capital cultural herdado da família e da escola em contraponto a um maior conhecimento das questões cotidianas. O duelo entre ajudar a família e estudar, coloca o jovem em situação marginal com os instrumentos intelectuais, portanto, possui maior dificuldade com o capital linguístico e o capital escolar. Sendo assim, as instituições de ensino superior recebem um acadêmico com vontade de aprender, mas com dificuldades eminentes ligadas às suas experimentações sociais anteriores. Desse modo, o acadêmico precisa conhecer e compreender como funciona o sistema educacional superior para estabelecer uma cultura do pertencimento social. A clivagem dos seus conhecimentos rurais anteriores ao ingresso no ensino superior é pouco explorada até mesmo em cursos voltados à ciência rural. Nesse sentido, o conhecimento empírico é trocado pelo constante aperfeiçoamento do conhecimento técnico e teórico. Nessas articulações, a juventude rural cotista precisa refinar outras habilidades que destoam das angariadas até o momento.

A identidade social, de jovem rural, é aos poucos marginalizada para aflorar outras características que lhes colocam em condições de aceitação dos colegas de curso, a maioria de origem urbana empresarial. Tal como observado por Elias e Scotson (2000), a distinção de status dos grupos sociais em que determinada comunidade estabelece entre si são complexas e nem sempre perceptíveis às pessoas de fora. Neto, Medeiros e Catani (2014) descrevem que existe uma convivência harmoniosa dos estudantes e os não bolsistas na faculdade, porém, diante da diferença de acesso a bens materiais e culturais, sentem resistência para fazê-lo em outros espaços.

As experiências simbólicas, materiais e culturais da juventude rural são, acentuadamente, distintas das experiências da juventude urbana. No ensino superior são mais efervescentes em função da tentativa de legitimação do futuro profissional na área e também das diferenças de classe. O habitus do jovem rural, bolsista do Prouni, é diferente do habitus do jovem bolsista de origem urbana, bem como ambos diferem amplamente do jovem urbano não bolsista. Para Bourdieu (1989), o habitus é uma aptidão de certa estrutura social ser incorporada pelos agentes por meio de um sistema de disposições do sentimento, do pensamento, da percepção e da ação. A vida cotidiana e a vida escolar dos jovens rurais são reflexos do passado no que tange ao habitus, isto é, o modo de vida é produto de uma incorporação histórica que consente a assimilação do adquirido histórico. As diferenças entre as dimensões no campo acadêmico entre os bolsistas e não bolsis- 
tas prevalecem quando a instituição de ensino internaliza e reproduz uma matriz disciplinar que legitima o campo dos jovens que tiveram maiores oportunidades de interação social, fortalece a reprodução da classe dominante e condiciona a todos adequarem-se para cultivar a cultura do pertencimento acadêmico e profissional. A padronização do habitus urbano e das classes dominantes se fortalece com o poder econômico que move o mercado de trabalho. $\mathrm{O}$ bolsista rural rapidamente compreende essa configuração no espaço social e traça estratégias para imersão à cultura do pertencimento e da legitimação profissional.

O jovem rural, bolsista do Prouni, possui uma característica peculiar, pois tem inculcado nas suas experiências vividas que as dificuldades do trabalho rural são eminentes. Alguns ambicionam distinção durante o andamento do curso para romper com o limite da hipossuficiência econômica da família. Outros buscam conhecimentos para habilitá-los a desenvolver uma atividade agropecuária com maior qualificação. Em certa medida, a bolsa do Prouni possibilita duas encruzilhadas - entre a qualificação para permanecer no meio rural e a qualificação para angariar empregos urbanos que possam oferecer melhores condições de vida. A ruptura com a raiz rural ocorre, em especial, quando o jovem não consegue uma bolsa na sua região. Portanto, precisa se deslocar para outro território no intuito de cursar o ensino superior numa instituição privada. Nesse caso, a possibilidade do jovem retornar ao território de origem é menor, pois se aumentam as relações sociais, as redes de contato, os jovens visualizam oportunidades em empresas do setor ou até mesmo nas universidades públicas. Quando o jovem instala-se em outra cidade para receber a bolsa que lhe dá acesso ao curso superior, o vínculo com a família e os laços de amizade locais já não são mais preponderantes para retornar à região.

Outra constatação é a dificuldade financeira da família para que o jovem permaneça no curso superior em uma instituição fora do seu município. Dessa maneira, uma das políticas criadas para os bolsistas do Prouni foi a bolsa permanência, destinada excepcionalmente ao custeio das despesas educacionais do beneficiário de bolsa integral do Prouni, matriculados em cursos presenciais com no mínimo seis semestres de duração e cuja carga horária média seja igual ou superior a seis horas diárias de aula, conforme dados do Ministério da Educação (2015). Apesar desse incentivo, apenas os alunos matriculados em cursos integrais podem acessar a política educacional. Nessa acepção, o estudo de Felicetti e Fossatti (2014) realizou um mapeamento comparativo entre alunos de cursos de licenciatura bolsistas do Prouni e alunos não bolsistas e concluíram que é necessário um estruturado programa estudantil que forneça cobertura às suas outras demandas como alimentação, moradia, saúde e transporte, determinante para garantir a permanência na universidade e nas licenciaturas até a integralização do curso. 
Para o êxito do programa não é suficiente apenas a inserção no curso superior, dada a característica de origem do bolsista que é sua baixa renda, porque o investimento financeiro para as necessidades fisiológicas e de segurança durante o andamento do curso é um fator circunstancial para sua permanência. De outro modo, também se inclui a dedicação integral aos estudos, fato que não é possível caso o aluno bolsista necessite procurar um emprego distante da sua área em formação para manter-se na faculdade. Assim, as dificuldades de aumentar o capital escolar durante a faculdade é fragilizada, pois necessita focar em outras atividades não acadêmicas para garantir o futuro no curso. O bolsista rural está em constante apreensão para incorporar algumas características do habitus da sociedade urbana. A estruturação de vínculos sociais e profissionais tem relação direta com a determinação, em especial, quando o jovem rural projeta uma carreira no meio urbano, sendo que um retorno ao meio rural somente acontece quando suas estratégias não forem bem sucedidas.

Quando a intenção do bolsista rural é buscar um bom emprego, posterior a conclusão da graduação, está em permanente tentativa de diferenciação em relação aos seus colegas da IES privada. Esse comportamento é fruto do reflexo da alta concorrência no mercado de trabalho e do aumento da taxa de escolarização das classes sociais nos últimos anos. Para tanto, dedica-se horas de estudo, leituras e compreensão dos elementos técnicos com intuito de alcançar bons indicadores nos trabalhos de sala de aula e nas provas objetivas e dissertativas uma estratégia para atingir um alto desempenho, chamando atenção dos colegas e dos docentes. Em geral, esse perfil de acadêmico optou por morar na cidade próximo a instituição de ensino. Em alguns casos, os bolsistas rurais formados em instituições particulares buscam ingressar diretamente na pós-graduação (especialização ou mestrado) diante da percepção de que o mercado de trabalho está altamente concorrido com o acesso ao ensino superior. A estratégia faz parte do processo meritocrático de avaliação escolar que ranqueia os melhores alunos em detrimento de notas e desempenho escolar. De certa forma, estar entre os melhores acadêmicos da classe aumenta o potencial para chamar a atenção de uma rede social de trabalho futuro. O Ministério da Educação noticiou que o desempenho dos bolsistas do Prouni é superior ao dos alunos que ingressaram por meio do vestibular (SOUZA, [200-]). A própria percepção dos bolsistas, anotada por Neto, Medeiros e Catani (2014) aponta um maior rendimento escolar dos acadêmicos bolsistas calcados nos valores imateriais como esforço e dedicação. Conforme pesquisa da Associação Brasileira para o Desenvolvimento da Educação Superior (ABRAES, 2014), os acadêmicos das IES particulares com bolsas integrais do Prouni possuem as maiores notas gerais médias do Exame Nacional de Desempenho de Estudantes (Enade). As informações dirigem para uma legitimação dos resultados positivos da política educacional. Entretanto, 
ainda carece uma sistematização do rendimento dos alunos bolsistas do Prouni que têm origem do meio rural e uma política de incentivo educacional que rompa com a invisibilidade desse público.

O jovem rural, bolsista do Prouni, traz vários valores morais introjetados consigo ao cursar o ensino superior numa IES Privada. Nesse espaço, a percepção é de que esse benefício foi conquistado com valores imateriais - muita dedicação, esforço e merecimento -, fato que embute uma obrigação intrínseca de galgar bom desempenho e fortalecer-se no campo escolar. O bolsista rural sabe que o diploma é apenas um passaporte que permite transcender a barreira social, porém, não fornece garantias de sucesso profissional. Para tanto, dedica-se ao máximo para conquistar uma diferenciação dos colegas, fato que potencializa uma boa indicação para um emprego futuro, mesmo que sua intenção inicial possa ser retornar à propriedade. $\mathrm{O}$ jovem rural planeja diversas estratégias ao longo do curso, entre elas está em permanecer ou sair da propriedade, conforme as oportunidades que se apresentam durante sua trajetória no ensino superior.

Neto, Medeiros e Catani (2014), na pesquisa sobre a identidade social do jovem recém-formado que foi bolsista integral do Prouni, concluíram que quando os bolsistas assumem sua diferença em relação aos colegas e classificam-se como melhores, eles colocam em segundo plano as distinções de capital econômico, social e cultural, demonstram o sucesso escolar, colocam em xeque a manutenção das trajetórias sociais de seus colegas não bolsistas e acendem possibilidades para tornarem-se um novo tipo de sujeito.

A conversão e o acúmulo do conhecimento, pelo bolsista rural, durante a jornada acadêmica, não é suficiente para galgar êxito no mercado de trabalho. Essa constatação se assemelha às considerações de Neto, Medeiros e Catani (2014), quando observam que, apesar do alto rendimento, os estudantes não bolsistas continuam com maior leque de oportunidades e a distinção no desempenho escolar é o único "trunfo" a favor dos bolsistas. (NETO; MEDEIROS; CATANI, 2014). O empenho escolar também se deve a necessidade de cumprir as exigências da bolsa para atingir o critério mínimo de aprovação no semestre. É uma condição prioritária a manutenção da bolsa de estudos, sendo que o encerramento da bolsa provoca necessariamente o seu desligamento, pois a probabilidade de conseguir quitar a mensalidade e manter-se no curso é baixa.

O Prouni tem maior impacto em regiões que não existem instituições públicas de ensino superior. Nesse cenário, a política educacional criou oportunidades para os jovens pleitearem uma vaga e fortaleceu o sonho de qualificar-se numa IES próxima da casa da família. Porém, o investimento e expansão das IES públicas são necessários para efetivação do processo de universalização e democratização do ensino superior no Brasil. Apesar do avanço das políticas educacionais como o Prouni, essas são insuficientes para proporcionar amplo 
acesso aos jovens rurais, tampouco o acesso a toda a juventude que demanda por qualificação profissional.

A ação do Estado com as políticas educacionais que oportunizam vagas em cursos superiores têm guiado, mesmo que indiretamente, um exímio processo de transformação social no meio rural. O sistema de relações que unem as experiências do meio rural e os conhecimentos e habilidades técnicas das IES provocam um aumento na taxa de escolarização das pessoas de origem rural. Com efeito, a qualificação profissional pode atuar de diferentes formas no processo de desenvolvimento do território, seja para maximizar os fatores microambientais da unidade de produção da família, seja para trabalhar como agente de desenvolvimento no território, proporcionando suas habilidades e competências a disposição da sociedade.

\section{Considerações finais}

Os requisitos do Prouni não preveem um recorte sobre a reserva de vagas por sua condição espacial - rural ou urbano. Os critérios são eminentemente econômicos aliados a uma condição de desigualdade social, forma de inclusão ou exclusão da política educacional. A renda anual da família rural é muito volátil, varia anualmente, dependendo das condições climáticas, do mercado e de uma série de fatores que colocam em xeque a condição econômica da família. Em alguns momentos, os filhos das famílias se veem numa situação crítica, pois a renda ultrapassa levemente o critério indicado. Nesse sentido, caso consigam a vaga via nota do Enem, não se enquadram nas condições previstas.

No meio rural brasileiro, as condições dos jovens, filhos de agricultores familiares, são diversas. Há aquelas famílias bem estruturadas economicamente, existem as famílias com relativa estruturação e as famílias com insuficientes condições econômicas. Grosso modo, os filhos que acessam a política educacional são aquelas famílias que possuem relativa estruturação econômica, pois os gastos em torno da universidade ainda colocam a família numa condição peculiar. Alguns jovens chegam a procurar um emprego na cidade sede da universidade ou numa cidade próxima com objetivo de auxiliar a quitar os gastos relativos ao curso superior. A dedicação exclusiva dos acadêmicos no ensino superior tem potencial de acrescentar maior capital cultural ao longo do tempo, em especial, as competências teóricas envolvidas. Por outro lado, aliar as experiências práticas durante o curso introjeta uma bagagem vivencial importante para o acadêmico. Nesse sentido, para os jovens rurais que permanecem na 
agricultura durante o estudo superior há restrições de ambas as partes - acadêmico e instituição -, em especial, numa área que é desligada do seu cotidiano, com poucas incursões no processo de ensino-aprendizagem relacionadas às suas vivências em se tratando de um curso na área de ciências sociais aplicadas ou humanas, porque geralmente esses cursos não têm foco voltado para o meio rural. Por isso, ainda carecem instituições que criem e ofereçam cursos voltados à agricultura nas regiões interioranas do país, uma condição que transcende o escopo dessa política educacional.

A criação do Prouni minimizou a privação do acesso ao ensino superior aos candidatos hipossuficientes economicamente e, de certo modo, incluiu filhos de famílias agricultoras de baixa renda. A juventude rural até a década de 2000 era considerada invisível para as políticas públicas no país. Após uma série de estudos, pesquisas e protagonismo do jovem rural surgiram políticas públicas relacionadas, em especial, à produção agrícola. Essa intervenção não foi tão efetiva, pois o jovem enquanto herdeiro subordinado à família não possui os fatores de produção e está sujeito a vontade do núcleo familiar enfrentando um campo os conflitos internos diretamente relacionados com os pais. Em algumas situações, os herdeiros visualizam a educação superior como forma de romper com a subordinação familiar.

A educação é um meio de emancipação das pessoas. (MARTINS, 2005). $\mathrm{O}$ acesso ao ensino superior coloca o jovem rural com maiores conhecimentos, o que implica necessariamente em uma mudança cultural na unidade de produção familiar. Porém, em termos de políticas educacionais, a juventude rural ainda é invisível e passa marginalizada do processo das cotas, em especial, pela compreensão de que o critério baixa renda é suficiente para a inclusão no Prouni. O Ministério do Desenvolvimento Agrário (MDA) tem articulado algumas políticas como o Pronaf Jovem, direcionado, em especial, ao âmbito produtivo, mas carece de políticas de incentivo para atender os anseios de qualificação dos jovens da agricultura familiar, estratégia que auxilia a reduzir as privações e a desigualdade social. O Prouni transcende a concepção de política pública, mas a condição marginal da juventude rural é uma questão que merece ser debatida, em especial, pelo Ministério da Educação.

Por fim, a família rural valoriza de forma acentuada a educação dos filhos, em especial, a educação superior. Nos últimos anos, a crescente mobilidade rural, o avanço das Tecnologias de Informação e Comunicação (TIC) e o acesso dos filhos de agricultores no ensino superior estão dinamizando o meio rural e acenando novas perspectivas de ascensão social. Nessa perspectiva, as políticas educacionais, mesmo que acessadas ainda pela minoria de jovens rurais, aos poucos, têm provocado um processo de transformação social no meio rural brasileiro. 


\section{REFERÊNCIAS}

ABRAES. Associação Brasileira para o Desenvolvimento da Educação Superior. Instituições particulares de ensino superior e Prouni: o impacto do programa de inclusão sobre o desempenho de seus alunos no Enade. 2014. Disponível em: < http://pt.slideshare. net/BlogDoPlanalto/relatorio-estudo-impacto-prouni-mec>. Acesso em: 27 nov. 2015.

ANDRÉS, A. Programa universidade para todos (Prouni). Brasília, DF, Câmara dos Deputados, 2008. Disponível em: < http://www2.camara.leg.br/documentos-e-pesquisa/ publicacoes/estnottec/areas-da-conle/tema11/2008-124.pdf>. Acesso em: 27 nov. 2015.

BOURDIEU, P. O poder simbólico. Rio de Janeiro: Bertrand Brasil, 1989.

BOURDIEU, P. Las estrategias de la reproducción social. Argentina: Siglo Ventiuno, 2011.

BOURDIEU, P.; PASSERON, J. C. A reprodução: elementos para uma teoria do sistema de ensino. Tradução de Reynaldo Bairão. 4. ed. Petrópolis, Rio de Janeiro: Vozes, 2011.

BRASIL. Lei no 11.096, em 13 de janeiro de 2005. Institui o Programa Universidade para Todos - PROUNI, regula a atuação de entidades beneficentes de assistência social no ensino superior; altera a Lei no 10.891, de 9 de julho de 2004, e dá outras providências. Congresso Nacional, DF, 13 jan. 2005. Diário Oficial da União, Brasília, DF, 13 de jan. 2015. Disponível em: <http:/www.planalto.gov.br/ccivil_03/_ato2004-2006/2005/lei/ L11096.htm>. Acesso em: 11 nov. 2015.

BRASIL. Lei n ${ }^{\circ} 7.423$, de 17 de dezembro de 1985. Revoga a Lei no 5.465, de 3 de julho de 1968, que "dispõe sobre o preenchimento de vagas nos estabelecimentos de ensino agrícola", bem como sua legislação complementar. Congresso Nacional, DF, 17 dez. 1985. Diário Oficial da União, Brasília, DF, 7 de dez. de 1985. Disponível em: <http:// www.planalto.gov.br/ccivil_03/leis/1980-1988/L7423.htm>. Acesso em: 11 nov. 2015.

BRASIL. Lei $n^{\circ} .5 .465$, de 03 de julho de 1968. Dispõe sobre o preenchimento de vagas nos estabelecimentos de ensino agrícola. Congresso Nacional, DF, 03 jul. 1968. Diário Oficial da União, Brasília, DF, 3 de jul. de 1968. Disponível em: <http://www.planalto. gov.br/ccivil_03/leis/1950-1969/L5465.htm>. Acesso em: 11 nov. 2015.

CARVALHO, G.; ROSSETTO, M. Os avanços das políticas de juventude no meio rural. In: MENEZES, M. A.; STROPASOLAS, V. L.; BARCELLOS, S. B. (Orgs.). Juventude rural e políticas públicas no Brasil. Brasília: Presidência da República, 2014. p.15-16.

CATANI, A. M.; GILIOLI, R. S. P. O prouni na encruzilhada: entre a cidadania e a privatização. Linhas Críticas, Brasília, v. 11, n. 20, p. 55-68, jan./jun. 2005.

CATANI, A. M.; HEY, A. P.; GILIOLI, R. S. P. Prouni: democratização do acesso às instituições de ensino superior? Educar em Revista, Curitiba, v. 29, p. 125-140, 2006.

ELIAS, N.; SCOTSON, J. L. Os estabelecidos e os outsiders: sociologia das relações de poder a partir de uma pequena comunidade. Rio de Janeiro: Jorge Zahar, 2000. 
FELICETTI, V. L.; FOSSATTI, P. Alunos Prouni e não Prouni nos cursos de licenciatura: evasão em foco. Educar em Revista, Curitiba, Brasil, n. 51, p. 265-282, jan./mar. 2014.

MARTINS, J. S. Cultura e educação na roça, encontros e desencontros. Revista USP. São Paulo, n. 64, 2005, p. 28-49.

NETO, R. D. M.; MEDEIROS, H. A. V.; CATANI, A. M. Percepções de bolsistas Prouni acerca do pertencimento ao ensino superior privado. Linhas Críticas, v. 20, p. 583-603, set./dez. 2014.

OLIVEN, A. Inclusion Policies in the Brazilian System of Higher Education: the public and the private sector. Journal of US-China Public AdministrZhong Gonggong Guanli, v. 9, p. 1302-1310, nov. 2012.

PROUNI. Bolsa Permanência. 2015. Disponível em: <http://prouniportal.mec.gov.br/ bolsa-permanencia>. Acesso em: 27 nov. 2015.

REDIN, E. Familia rural e produção de tabaco: estratégias de reprodução social em Arroio do Tigre/RS. 305 f. Tese (Doutorado) - Programa de Pós-Graduação em Extensão Rural, Universidade Federal de Santa Maria, Santa Maria. 2015.

REDIN, E. Jovem rural em questão. Sociais e Humanas, Santa Maria, v. 25, n. 1, p. 123-139, jan./jun. 2012.

REDIN, E.; SILVEIRA, P. R.C. Juventude rural: experiências e perspectivas. In: SANTOS, V. F.; VELA, H. A. G.; SILVEIRA, P. R. C. (Orgs.). Educação rural no mundo contemporâneo. 1. ed. Santa Maria: UFSM, 2012. p. 175-208.

SEN, A. Desenvolvimento como liberdade. São Paulo: Cia das Letras, 2000.

SISPROUNI. Sistema informatizado do Prouni. Bolsistas por sexo. 2014. Brasília. Disponível em: < http://prouniportal.mec.gov.br/images/pdf/Representacoes_graficas/ bolsistas_por_sexo.pdf>. Acesso em: 24 nov. 2015.

SISPROUNI. Sistema informatizado do Prouni. Bolsistas Região Sul. 2015. Brasília. Disponível em: < http://prouniportal.mec.gov.br/images/pdf/Representacoes_graficas/ bolsistas_por_uf_regiao_sul.pdf>.Acesso em: 10 nov. 2015.

SOUSA, S. Alunos do Prouni têm ótimo desempenho. Brasília. Disponível em: < http:// portal.mec.gov.br/component/content/article?id=4881:sp-476865137>. Acesso em: 27 nov. 2015.

STROPASOLAS, V. L. Os dilemas da juventude no processo sucessório da agricultura familiar. In: RENK, A.; DORIGON, A. (Orgs.). Juventude rural, cultura e mudança social. Chapecó: Argos, 2014. p. 139-162.

Texto recebido em 26 de janeiro de 2016. Texto aprovado em 15 de agosto de 2016. 